\title{
The Role of Self-Management Practices, Competency, and Time Management Practices of the University Undergraduates on Their Success: A Conceptual Model Development
}

\author{
T. L. Sajeevanie \\ Department of Human Resource Management \\ Faculty of Management Studies and Commerce \\ University of Sri Jayewardenepura, \\ Colombo, Sri Lanka.
}

\begin{abstract}
Most of the university undergraduate students are having very good academic results at their secondary school education. However, when they enter to the university, very little amount of students pay more attention compared with their previous studies, very limited number of students continue their studies as previously. Majority of the students pay less attention compared with their Advance level. In addition, the most serious issue is there are some students who does not pay considerable level of attention for their university studies and them very unsuccessful at the university level. Some of they cannot get at least general pass at the desired time. Another important factor is majority of them do not have clear life plan. Hence, the major outcome of this study is to develop a conceptual model to test the importance of having proper self-management practices and time management practices. In addition, this study has identified the importance of identify the methods of how to disseminate the knowledge of self-management and time management practices. And this study suggest for future researchers to conduct research studies on how to disseminate the knowledge and enhancing the selfmanagement competency, initially at the university level and ultimately at the national level.
\end{abstract}

Keywords:- Self-Management Practices, Students Success and Time Management Practices.

\section{INTRODUCTION}

University education should be able to gain more than just obtaining a paper qualification. (Kadiyone \& Hafiar, 2017). Hence, internaly students when they enter to the university they should manage themselves properly to achieve the goals of their university education and their other life goals. Among these goals, academic success should be the most prioritized goal in their goals list. Most of the students do not have a clear life plan with them. Under the management education, they learn many management fields relevant to organization's management. However, they do not pay considerable attention on SelfManagement. They pay less or no attention on selfdiscipline, time management, self-leadership etc.

\section{OBJECTIVE OF THE STUDY}

Doing a research study on what are the factors affecting to the university student's success, is very critical. The researcher personally involved with interviews with few undergraduates relating to their strategic life plan, it was found majority of them did not have a clear life plan. However, having successfully completing a very competitive examination all of them are enter to the university. Unfortunately, some students cannot perform as they were expected. There were many reasons for this situation. Some students are misleading at the university, engaging some unethical behaviors, which are very seriously harmful to their success, university success, country success, and ultimately affecting to the global success. Hence, this study attempting to develop a model to test the impact of Self-management, time management practices on their success. The problem statement of the study is "what is the role of Strategic Self-management Practices and time management practices of the university undergraduate on their success? ".

Hence, the first objective of this study is to develop a model to explore the impact of Strategic Self-management Practices, Student's Competency and Time Management Practices of the undergraduate University Students on their success and the second objective of the study is how to disseminate the knowledge of Self-Management and Time Management practices to university students.

\section{SIGNIFICANCE OF THE RESEARCH}

Globally, self-mastering and self-leadership is very popular. However, in Sri Lankan context it is very hard to find formal education on self-mastering and selfleadership. Even 'time management' it is hard to find as a subject in Sri Lankan universities management courses. As Sri Lankans, we have very good values and qualities. However, we are very poor in managing our time. We do not much consider the importance of our time, importance of others time, importance of punctuality, and importance of prioritization. One of the major reason may be lack of formal education on this area. Even in management courses, it is very difficult to find a subject relevant to self- 
management or personal management. There only very specific courses having these subjects in their curriculum. In global context, it is hard to find strategic selfmanagement literature. Hence, this study address some theoretical and empirical gaps in the area of selfmanagement practices, and time management practices and, developed a conceptual model to test.

\section{LITERATURE REVIEW}

Successful students are not simply individuals who know more than others. They also should have effective and efficient learning strategies for accessing and using their knowledge, can motivate themselves, and can monitor and change their behavior when learning does not occur. One of the first uses of the term self-management appeared in a book on the rehabilitation of chronically ill children written by Thomes Career since the mid-1960s he and colleagues at the children's Asthma Research Institute and hospital have been using the term in conjunction with their pediatric Asthma program. However, as Sajeevanie (2020) explained Self-management has very broad meaning than self-care management and it gives more benefits.

\section{Self-Management}

Ochs (2017) has mentioned three simple strategies to improve our self-management. They are manage your breath, activate your strengths, and consider your beliefs. Self-Management techniques can be identified as selfobservation, goal specification, cueing strategies, incentive modification, and rehearsal. Organizational learners can help subordinates to develop their self-management skills. As explained by Frayne and Geringer (2000) training in self-management skills significantly improved job performance as assessed through both objective and subjective measures. There are variety of terms have been used to describe self-regulatory process such as selfmanagement, self-leadership, self-reinforcement, and behavioral self-management (BSM). BSM has been defined as 'deliberate regulation of stimulus cues, covert processes, and response consequence to achieve personally identified behavioral outcome, (Saks and Ashforth, 1996, p. 303). Individuals who practice BSM have been found to display greater levels of performance, motivation and are better able to manage and cope with obstacles (Saks \& Ashforth). As they mentioned self-management related to cognitive, affective and behavioral outcomes. They have identified few studies on investigating self-management in organizational settings. The authors have quoted Aldag et al (1983) self-reinforcement has positively related to job involvement and several factors of job satisfaction. Recently BSM has received a considerable amount of attention in research on training. Self-management training intervention improved trainee's acquisition and maintaining of complex interpersonal skills.

The success ultimately depends on individual behavior. This idea can be empathize citing "the seven habits of highly effective people" by Stephen R. Covery. Covey (2013) has explained the seven habits for effectiveness. These habits are be proactive, begin with the end in mind, put first things first, think win-win, seek first to understand then to be understood, synergize, and sharpen the saw. Further he has explained that "habits becomes the basis of a person's character, creating an empowering center of correct maps from which an individual can effectively solve problems, maximize opportunities, and continually learn and integrate other principles in an upward spiral of growth" (p.61). He also has introduce a principle called the "P/PC balance". It has been nicely explained this principle using the fable of goose and the golden egg (please refer the annexure for the story). As explain here more people identify success from the golden egg paradigm: the more you produce, the more you do, the more effective you are. Covery has explained success is a function of two things: what is produced (the golden eggs) and the producing asset or capacity to produce (the goose). Hence, as individuals it is our responsibility to manage these two aspects successfully. The success is depends on the P/PC balance. P stands for production of desired results, (Golden eggs). PC stands for Production capability, the ability or the asset that produces the golden eggs. More broadly, self-management focus on the P/PC balance.

\section{$>$ Personal Mastery (Self-Mastering)}

Self-mastering also can be identified as relevant concept to self- Management. According to Senge (1990) personal mastery is the discipline of continually clarifying and deepening our personal vision, of focusing our energies, of developing patience, and of seeing reality objectively. It is about beyond competence and skills, although it involves them. In addition, it is about beyond spiritual opening, although it involves spiritual growth. The most important point is people with high level of personal mastery live in a continual learning mode. Personal mastering, is not a something you possess, it is a process. Moreover, it is a lifelong discipline. Most advantage is people with a high level of personal mastery are aware their ignorance, their incompetence, their growth areas. In addition, they are deeply self-confident. The five that Peter Singe (1994) identifies are said to be converging to innovate learning organizations. They are Systems thinking, Personal Mastery, Mental models, Building shared vision, Team learning. Systems theory's ability to comprehend and address the whole and to examine the interrelationship between the parts provides, for Peter Senge, both the incentive are the means to integrate the disciplines.

\section{$>$ Academic Self-management}

Early it was thought the intelligence was the main factor determining academic success. Then it was identified to become more successful learner by using appropriate strategies to manage their motivation, behavior and learning. The successful students self-manage or control the factors influencing their learning. They establish optimum considerations for learning and remove obstacles that interfere with their learning. That type of students can be identify as self-regulated, self-directed, strategic and active. Specially, university students are been selected to the university. They have very high marks for the advance level examination. However, the issue is some students are 
ISSN No:-2456-2165

very poor performers at the university level. When discussing the reasons for low achievements, it was not found that they have serious learning disabilities. Some students believe that if they simply spend good deal of time studying, they will be successful. However, here the most important point is successful learners do work hard, but they realize that how they study is more important than how much time they spend studying. According to Zimmerman and Risemberg (1997), following are the six major component of academic self-management,
- Motivation

- Method of learning

- Use of time

- Physical Environment

- Social Environment

- Monitoring Performance

Following figure shows the interrelation between selfmanagement and academic behavior.

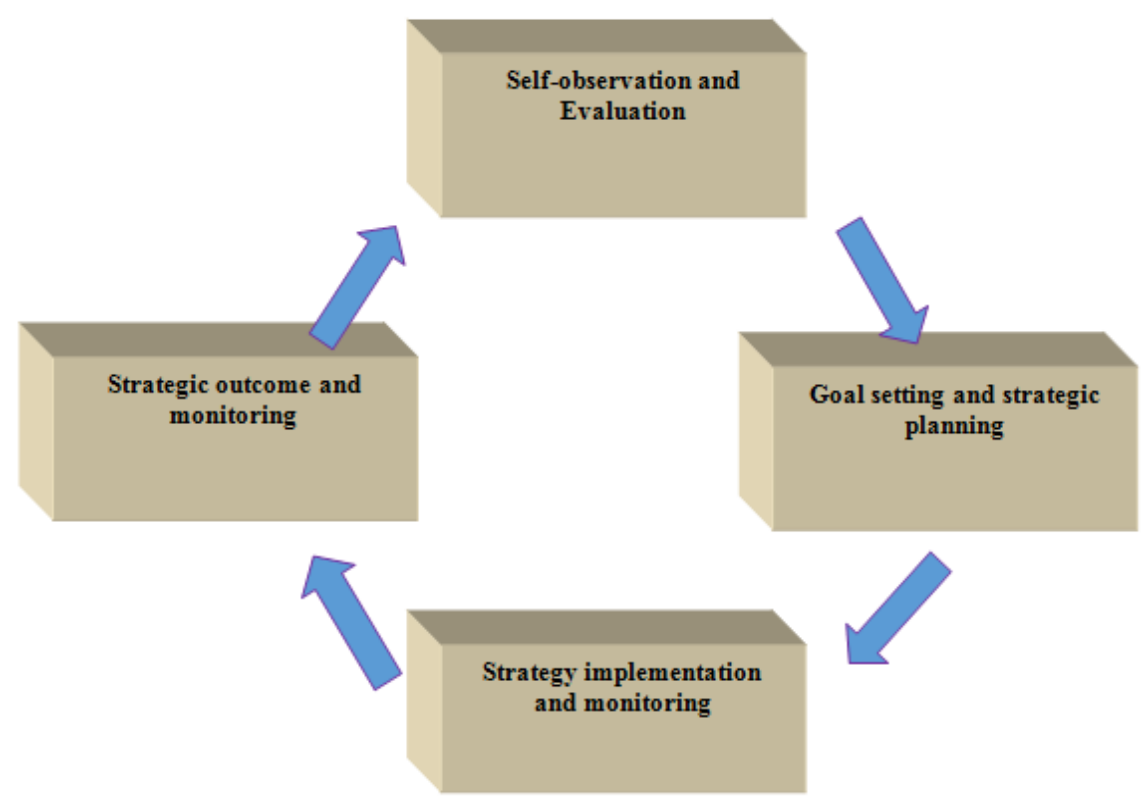

Fig 1:- The interrelation between self-management and academic behavior. Source: Ziumerman et al. 1996)

\section{Self-Leadership}

In general, leadership is to enhance the capacity of all people work productivity toward common goals. Leaning organizations are organizations where people continually expand their capacity to create the results they truly desire, where new and expansive patterns of thinking are nurtured, where collective aspiration is set free, and where people are continually learning to see the whole together (Senge et al, 1994). From normal leadership to self-leadership is very critical to individual development and organizational development. One aspect is 'generative learning', which means learning that enhances our capacity to create. Selfleadership is a process through which individuals control their own behavior, influencing and leading themselves with specific sets of behavioral and cognitive strategies, (Neck \& Houghton, 2006). According to him, selfleadership concept first emerged in the mid-1980s, which was rooted in clinical self-control theory. Considerable research has revealed positive effects of self-leadership on work-related outcomes (Stewart at el. (2010). They have further explained according to a study based on 308 companies over a 22 - year's period has found increasing individual self-control to be one of the most effective methods for improving employee productivity. Moreover, Self-leadership has been shown to result in greater career success for individuals. Moreover, increased self-leadership has been linked with greater job satisfaction and reduced absenteeism. Self-managing teams literature of the late 1980s prescribed self-leadership among team members as a crucial part of the self-managing process. (Neck \& Houghton, 2006).

\section{Time Management Practice}

"Time management is a special competence that one should possess in order to achieve success and progress of success on the job life and other aspects of the life" (Opatha, 2010, p.154). As he explained, time has very specific characteristics; such as time factor as individuals, we do not have control over. Everybody have same amount of time per day. Hence, it is very critical to manage the time in order to get the maximum benefits from available time. Unless unknowingly we are wasting our time. The most important factor is as human beings we should understand this and should inculcate time management practices to our life. Educators have found a relation between time management and academic achievement. Students with better time management practices tend to have a higher grade-point average (GPA) than the students with poor time- management practices. They have mentioned why time management appears to be so important in determining academic success as use of time impacts self-management. However, there are only few 
studies on time management has done in Sri Lankan Context (Sajeevanie, 2018).

\section{Academic success}

Academic success of the students can be defined and can be measured in many ways. The academic success of the university students is very critical. In generally they spend three or four years with in the university. Newton et al (2010) have found there are six factors affecting college student's success. Academic self-efficacy, organization attention to study, stress and time press, involvement with collage activity, emotional satisfaction and class communication. There are several for achieving low performance at university level. Following is a quotation from Dembo and Seli (2011, p 45) regarding student's low achievements.

"When discussing the reasons for low achievement we are not including students who have serious learning disabilities, poor language skills or who have experienced an inadequate education because of factors beyond their control. Instead, we are referring to students who should be achieving higher than their present performance. In many cases, more than one explanation may be appropriate for a given student".

\section{METHODOLOGY}

Since this is a conceptual paper, the main objective is to develop a conceptual framework. Hence, the researcher mainly concerned with the existing literature. The second objective of this study is "how to disseminate the knowledge of Self-Management to university students". This objective was achieved through interviewed data. Data was collected from structured interviews following convenient sampling method. The Sample was consisted with 10 professors in state sector universities in Sri Lanka. Collected data was analyzed using qualitative technique.

\section{CONCEPTUAL MODEL DEVELOPMENT}

Sekaran and Bougie (2013, p.77) has explained conceptual framework is the foundation on which the entire deductive research project is based. It is a logically developed, described, and elaborated network of associations among the variables deemed relevant to the problem situation and identified through such processes as interviews, observations, and literature review.

As explained above self-management is significant for the undergraduates. They should success at the university. That mean they should achieved their short-term objectives. This achievement of their short-term objectives can be identified as student's success. According to Sajeevanie (2020) Self-management has been identified as SelfPerformance Management, Self-Care Management, SelfMastering, Self-Quality Management, Self-Career Management, Self-Finance Management, SelfDevelopment, Self-Marketing Management, and SelfDisciplinary Management. The independent variable of following conceptual framework is Self-Management. The dimensions of Self-management has been identified as Self- Development, Self-Quality Management, SelfMastering, Self-Discipline. These are the most relevant self-management practices to university students. However, the success of the students intervene their competency. Based these arguments the following conceptual framework has been developed. The conceptual model consist with one independent variable; Self- Management practices, One dependent variable; students success, two moderating variables; students competency, time management

\section{Conceptual Model}

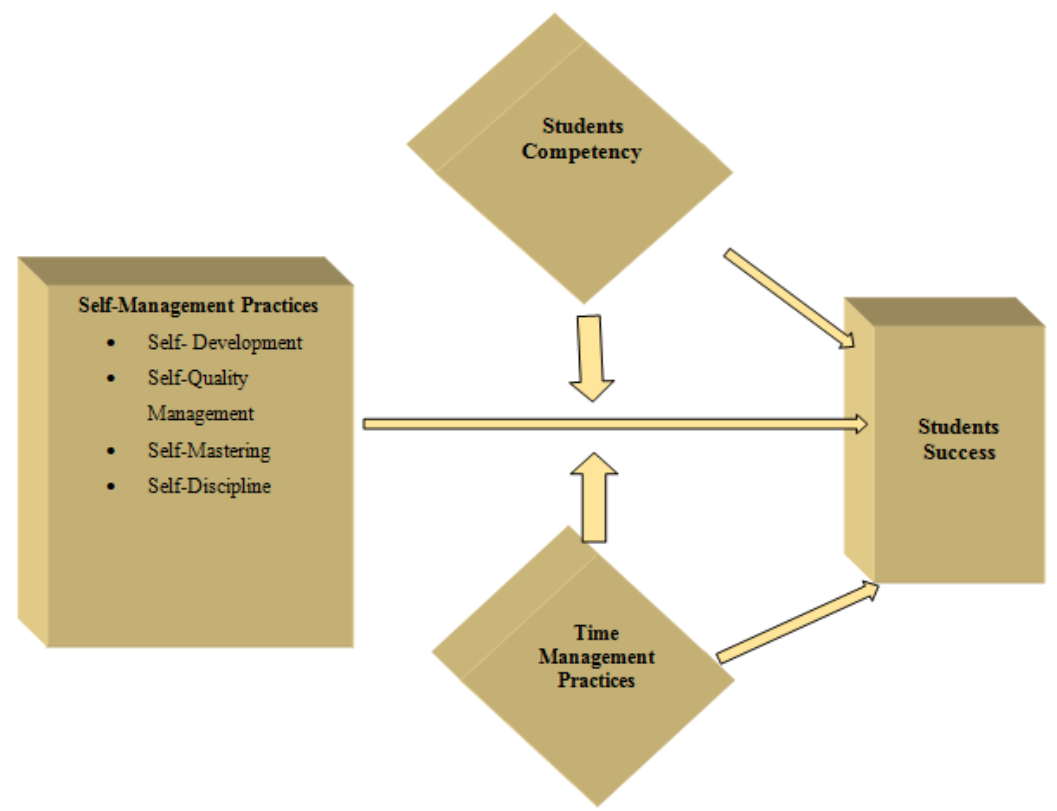

Fig 2:- Conceptual Model

Source: Developed by Author 


\section{CONCLUSION AND FUTURE RESEARCH SUGGESTIONS}

According to the finding of the interviews, the best way to disseminate the knowledge of self-management and time management is to be included in their curriculum. In addition to that, encourage them for self-studies, publish reading materials on these areas are the other suggestions. Hence, the researcher would like to propose as implications it is more critical to encourage university students to study on these areas and encourage them to practice these as their day to day practices. As future research suggestions the researcher like to propose the future researchers to conduct studies to test the above developed conceptual framework. Then it will be able to justify the importance of SelfManagement, Time-Management practices on the success of undergraduate students.

\section{REFERENCES}

[1]. Covey, S.R. (2013). The 7 Habits of Highly Effective People, Simon \& Schuster, London.

[2]. Dembo.M.H. and Seli H. (20011). Motivation and Learning strategies for college success. A selfmanagement approach, $3^{\text {rd }}$ ed. Roulledge, London.

[3]. Drucker P.F. (2005). Managing oneself. Harvard Business Review January

[4]. Frayne, C. A., and Geringer, J. M. (2000). Selfmanagement training for improving job performance: A field experiment involving salespeople. Journal of Applied Psychology, 85(3), 361-372.

[5]. Kadiyono, A.L. and Jaguar H. (2017). The role of academic self- management in improving students' academic achievement. Ideas for $21^{\text {st }}$ century education. The Asian Education Symposium (AES2016)

[6]. Kate R. Lorig, and Halsted R. H. (2003). Selfmanagement education: History, definition, outcomes, and mechanisms, Annals of Behavioral Medicine, Volume 26(1), Pages 1-7.

[7]. Lorig, K.R. and Holman H.R. (2003). Self Management Education: History, Definition, Outcomes, and Mechanisms. Annuls of Behavioral Medicine 26(1).

[8]. Manz, C.C. and Sims, H.P. (1980). Self-Management as a substitute for leadership: A social learning theory perspective. Academy of Management Review, 5(3).

[9]. Neck, C.P and Houghton, J.D. (2006). Two decades of self-leadership theory and research: Past development, present trends, and future possibilities, Journal of Managerial Psychology.

[10]. Ochs L. (2017). Improve your self-management strategies in 5 minutes a day.

[11]. Opatha, H.H.D.N.P. (2010). Personal Quality, Author, Sri Lanka.

[12]. Paulauskas S and Paulauskas , A. (2008). The virtualics and strategic self-management as tools for sustainable development, Ukio Technologinis ir Ekonominis Vystymas, 14:1, 76-
[13]. Sajeevanie, T.L. (2018) Time Management Practices and Academic Success of the University Lecturers in Sri Lanka, International Journal of Business and Administration Studies, Vol 4(2), 78-85

[14]. Sajeevanie, T.L. (2019). Prioritization and Academic Success of the University Lecturers in State Universities in Sri Lanka. $2^{\text {nd }}$ Bangkok Chapter on Contemporary Research Methods in Social Development and Business Management (CSDBMAug-2019), Bangkok, Thailand.

[15]. Sajeevanie, T.L. (2020). Importance of SelfManagement and Future Research Thoughts: A critical Review Perspective, International Journal of Creative Research Thoughts: A Critical Review Perspective, Vol 8 (7), 412-426.

[16]. Saks, A.M. and Ashforth, B.E. (1996). Proactive Socialization and Behavioral Self-Management, Journal of Vocational Behaviour, 48, 3001-325.

[17]. Sekaran, U and Bougie R. (2013). Research Methods for Business, A skill-Building Approach, Nisha Enterprises, Sahibabad.

[18]. Stewart, G.L., Courtright, S.H. and Menz, C.C. (2010). Self-Leadership:A Multilevel Review. Journal of Management, http://jom.sagepub.com/

[19]. Sue K. G. (1997). Underprepared community college students: Characteristics, persistence, and academic success. Community College Journal of Research and Practice. 21(1), 47-56.

\section{ANNEXURE: THE FABLE - THE STORY OF THE GOOSE AND THE GOLDEN EGG.}

A poor farmer who one day discovers in the nest of his pet goose a glittering golden egg. At first, he thinks it must be some kind of trick. But as he starts to throw the egg aside, he has second thoughts and takes it in to be appraised instead. The egg is pure gold! The farmer can't believe his good fortune. He becomes even more incredulous the following day when the experience is repeated. Day after day, he awakens to rush to the nest and find another golden egg. He becomes fabulously wealthy; it all seems too good to be true.

But with his increasing wealth comes greed and impatience. Unable to wait day after day for the golden eggs, the famer decides he will kill the goose and get them all at once. But when he opens the goose, he finds it empty. There are no golden eggs- and now there is no way to get any more. The farmer has destroyed the goose that produced them.

Source: Stephen R. Covey (2013) The seven habits of highly effective people. P. 61 